\title{
Das Práticas de Gestão de Grandes Projetos Urbanos
}

\section{Management Practices of Urban Mega Projects}

\author{
Letícia Nerone Gadens \\ Doutoranda do Programa de Pós-Graduação em Gestão Urbana da \\ Pontifícia Universidade Católica do Paraná (PUCPR). \\ E-mail: letícia_gadensळyahoo.com.br \\ Letícia Peret Antunes Hardt \\ Doutora em Engenharia Florestal. Pesquisadora e Professora do \\ Programa de Pós-Graduação em Gestão Urbana da Pontifícia \\ Universidade Católica do Paraná (PUCPR). \\ E-mail: I.hardtळpucpr.br \\ Klaus Frey \\ Doutor em Ciências Sociais pela Universidade de Konstanz, Ale- \\ manha; Pesquisador e Professor do Programa de Pós-Graduação \\ em Planejamento e Gestão do Território da Universidade Federal \\ do $A B C$. \\ E-mail: klaus.freyळufabc.edu.br
}

\section{Resumo}

O presente artigo busca contribuir para o maior aprofundamento da discussão sobre um fenômeno comum a algumas cidades brasileiras: os Grandes Projetos Urbanos (GPUs). Para tanto, parte-se da assertiva de que se trata ainda de um conceito em formação na literatura acadêmica. Nesse sentido, baseado em uma pesquisa bibliográfica, o artigo discute seu delineamento conceitual e sua implementação no cenário brasileiro a partir da década de 1970, estabelecendo relações com as práticas e modelos de gestão urbana presenciados ao longo das últimas quatro décadas de análise. Os resultados evidenciam aspectos similares e díspares no debate teórico sobre GPUs, enquanto as conclusões demonstram a necessidade de maior aprofundamento conceitual do tema, tendo em vista a relevância da discussão e reflexão sobre esse tipo de intervenção urbanística no planejamento do território das cidades contemporâneas.

Palavras-chave: Grandes Projetos Urbanos; Mega Intervenções Urbanísticas; Gestão Urbana. 


\section{Abstract}

This article aims to contribute to further deepen the discussion of a phenomenon common to several Brazilian cities: the Urban Mega Projects (UMPs). To do so, it starts from the assertion that it's still an emergent concept in the academic literature. Based on a bibliographic research, the article discusses its formation and implementation in the Brazilian context since the 1970s, establishing relationships with the practices and models of urban management witnessed over the last four decades of analysis. The results reveal similarities and dissimilarities in the theoretical debate on UMPs, while the final conclusions show the need for deepening conceptual reflections on this topic, as it is a central question on this kind of intervention in territorial planning of contemporary cities.

Keywords: Urban Mega Projects; Mega Urban Interventions; Urban Management.

\section{Introdução}

Este artigo tem como objetivo principal contribuir para a discussão conceitual sobre Grandes Projetos Urbanos (GPUs), considerando as mudanças de gestão e de controle do Estado sobre essas intervenções no cenário brasileiro. A relevância do tema reside no destaque dispensado pela academia ao debate de projetos dessa natureza, além da necessidade de compreensão do assunto de forma mais aprofundada, tendo em vista que o conceito de GPU é objeto de contínuas controvérsias e que seus riscos e impactos merecem maior aproximação no âmbito acadêmico.

No cenário nacional, podem ser mencionados alguns GPUs de destaque, os quais vêm motivando várias pesquisas, contribuindo, em especial, para os questionamentos que embasam esse trabalho. Nesse contexto, as obras relacionadas aos Jogos Panamericanos do Rio de Janeiro, em 2007, consistem em um grande conjunto de intervenções das quais se evidencia a Vila Olímpica e o Estádio João Havelange (Engenhão). Por sua vez, o projeto Centro Dragão do Mar de Arte e Cultura, em Fortaleza, cujas obras foram concluídas no final da década de 1990, corresponde a um complexo formado por edificações interligadas por passarelas, situadas entre o velho cais de Iracema e o centro antigo da cidade. 0 projeto "Ver o Peso" de Belém, também datado do final da década de 1990, compreende a reabilitação de um dos maiores mercados da América Latina, formado por um conjunto de edificações de interesse histórico. Esses exemplos ilustram, em realidades urbanas distintas, que a inserção de GPUs nas cidades brasileiras tem sido parte constituinte das ações de planejamento e gestão.

Dessa forma, o problema central do trabalho tem foco na observação de que os diferentes modelos de gestão, aplicados nas quatro décadas de análise (1970 - 2000), pautaram enfoques distintos na aplicação de GPUs, que ora se referem a grandes obras de infraestrutura, ora a intervenções de cunho estratégico. Dessa forma, a hipótese central da pesquisa fundamenta-se na possibilidade da utilização de GPUs como reforço dos modelos de gestão propostos. 
Assim, o estudo é estruturado a partir de um questionamento conceitual que procura evidenciar as principais abordagens sobre o tema a partir da década de 1970, quando começa, no Brasil, a proposição e implementação de grandes obras urbanas. 0 delineamento de conceitos inicia com a abordagem positivista e crítica do tema, sendo, na sequência, a proposição de GPUs relacionada aos modelos vigentes de gestão. Procura-se destacar também a participação popular nos modelos de análise. Nas considerações finais é dada ênfase aos principais aspectos verificados, com enfoque na gestão urbana acerca da implementação dessas grandes intervenções urbanísticas.

\section{Da conceituação sobre Grandes Projetos Urbanos}

Embora trate-se ainda de um conceito em elaboração, várias dimensões de caracterização dos GPUs podem ser encontradas na literatura. Assim, podem corresponder a operações físicas que, de modo geral, envolvem consideráveis somas financeiras e promovem alterações expressivas no espaço urbano (Hardt e col., 2008). Ultramari e Rezende (2007), por sua vez, reforçam o pressuposto de que os GPUs correspondem a instrumentos de política pública, cuja escala projetual se distingue do entorno, sendo capazes de causar impacto para além dos seus limites imediatos. Santos (2006, [s.p.]) amplia esse debate ao mencionar que:

As transformações no espaço urbano são fruto não só das relações intraurbanas, mas de relações regionais e globais, já que a cidade não é um lugar fechado em si, ela assume relações que ultrapassam a esfera local e regional, e isto exige que se tenha uma visão da cidade inserida num contexto políticoeconômico mais abrangente.

Dessa forma, a implantação de determinado GPU promove ostensivas alterações no espaço urbano, cujos impactos podem ser observados além dos limites da área para a qual foi projetado. Sob essa ótica, e considerando a premissa de que os riscos assumidos estão diretamente vinculados ao fenômeno da globalização e ao modo de vida de uma sociedade (Beck, 1992), os impactos resultantes da implantação de GPUs ainda merecem maior discussão da academia, com a análise dos riscos e das consequências de suas atividades.

Conceitualmente, os GPUs também são interpretados como iniciativas de renovação urbana, concentradas em determinados setores da cidade, que envolvem agentes públicos e privados, cujos investimentos e intervenções seguem as diretrizes de um plano urbanístico apoiado no redesenho do espaço urbano, em especificidades legais ou em novas articulações institucionais e formas de gestão (Someck e Campos Neto, 2005).

No entanto, de acordo com Powell (2000), esse tipo de intervenção conta com uma multiplicidade de usos propostos, associados a situações de pósguerra, novas demandas de transporte, crescimento da mancha urbana e certas requisições culturais. Por outro lado, no cenário brasileiro sua implementação parece estar vinculada à recuperação de áreas com grande potencial para uso urbano, porém abandonadas e degradadas (Ultramari e Rezende, 2007).

Outro referencial associado ao conceito de GPUs diz respeito à obra de Altshuler e Luberoff (2003), que, considerando a experiência norte-americana, caracteriza GPUs como intervenções de vultoso desembolso de recursos públicos, em parceria com o setor privado, alterando tecidos urbanos para atendimento de novas demandas por transporte individual, relacionado com a era do automóvel. As divergências não se referem tanto às características de GPUs em si, ou aos critérios que permitem ou justificam a recorrência ao conceito, mas antes às suas implicações político-administrativas e urbanísticas e seu pano de fundo ideológico. Com base na literatura sobre o tema, é possível identificar duas correntes principais que discutem os GPUs. A primeira, considerada positivista, ressalta sua inserção em um processo amplo de planejamento estratégico, supostamente participativo. Essa linha não se atém à crítica específica dos interesses suscitados por intervenções dessa natureza. A caracterização de Del Rio ilustra bem esse viés positivista da seguinte forma:

Através de um planejamento estratégico entre poder público (viabilizadores), poder privado (investidores) e comunidades (usuários), identificam-se planos e programas que maximizem e compatibilizem os esforços e investimentos, e norteia-se a im- 
plementação integrada de ações e projetos a curto, médio e longo prazos. Os resultados positivos, por sua vez, realimentam o processo atraindo novos investidores, novos moradores e novos consumidores, e gerando novos projetos (DEL RIO, 200o, [s.p.]).

Autores com Borja e Castells (2000, p. 143), discutindo a emergência das grandes cidades latinoamericanas como atores político-econômicos no cenário global da nova era da informação, apresentam grandes esperanças quanto à cooperação entre os setores público e privado, buscando reconciliar as aspirações econômicas de grandes projetos com a participação democrática. Nesse âmbito, os autores reforçam a importância da participação ativa desses principais agentes para a conquista de amplo consenso de cidadania.

Por outro lado, a segunda corrente, com visão crítica à implantação de GPUs, contesta a própria possibilidade de um consenso democrático em torno de grandes projetos e adverte sobre os riscos envolvidos com a implementação de GPUs. De acordo com Moulaert e colaboradores (2003), trata-se de uma estratégia de dominação no âmbito territorial, ressaltando que na formulação de tais projetos reside a distribuição desigual de poder. Nessa mesma linha de pensamento, Harvey (200o) aponta que, para a viabilização dos GPUs, o poder público assume os riscos, enquanto o setor privado assume os lucros resultantes dessas intervenções.

Em ambos os posicionamentos frente aos GPUs, é relevante considerar que projetos dessa natureza consistem em uma intervenção de cunho exclusivamente urbanístico da cidade na qual são implantados, embora seus efeitos nem sempre recaiam nesse mesmo âmbito. Segundo Ferrán (2001), é preciso compreender esse deslocamento de causas e efeitos a fim de orientar as intervenções, reduzindo sentimentos de frustração experimentados por técnicos e governantes quando não obtêm os resultados esperados na implantação de um GPU.

Seja uma visão de exaltação ou um posicionamento de censura aos GPUs, a produção acadêmica sobre o tema tem evidenciado novas formas de atuação no espaço. Se, de um lado, são verificados limites e falta de consenso sobre o conceito e suas implicações, por outro, tem-se insinuações de tendências no planejamento urbano contemporâneo, ainda que as consequências e os riscos assumidos por essa postura urbanística mereçam aprofundamento de análise e reflexão, de modo a minimizar impactos negativos e ampliar suas potencialidades (Gadens e col., 2011).

A despeito da visão positivista e do posicionamento crítico, e frente aos delineamentos conceituais adotados para o tema, arrisca-se o estabelecimento de uma definição tipológica para os GPUs, considerando os aspectos comuns em sua conceituação. Dessa forma, com base na discussão proposta, tem-se, a princípio, quatro tipos básicos de GPUs, delimitados no Quadro 1, a seguir apresentado. Embora apresentem divergências de concepção, têm em comum dois critérios básicos citados como definidores de um Grande Projeto Urbano: o desembolso de grandes somas de recursos financeiros e as alterações ostensivas do espaço urbano. 0 enquadramento proposto, elaborado originalmente para esse estudo e base do seu desenvolvimento, tem por objetivo classificar as tipologias de GPUs frequentemente encontradas na literatura acadêmica.

Alguns tipos de GPUs são mais evidentes no Brasil durante a década de 1970, como obras que demandaram elevados investimentos públicos, a exemplo dos grandes empreendimentos hidrelétricos. Já a produção de marcos arquitetônicos e a revitalização de espaços provêm, muitas vezes, da necessidade de inserção da cidade em um cenário competitivo, na tentativa de viabilizar sua imagem em um contexto urbano global. Esses são os casos do Museu Oscar Niemeyer, em Curitiba, e da recuperação do Centro Histórico de Salvador. A promoção de megaeventos no Brasil pode ser exemplificada como GPU por meio dos Jogos Pan-americanos Rio 2007; no entanto, essa questão se tornará ainda mais relevante com a realização, no Brasil, da Copa do Mundo em 2014 e dos Jogos Olímpicos em 2016, garantindo destaque na discussão do tema.

A despeito dos objetivos suscitados pelos GPUs em diferentes épocas de sua implantação, um dos aspectos evidentes em todos os períodos diz respeito à necessidade de inserção das comunidades na discussão desses projetos, bem como a consideração dessas populações na elaboração e desenvolvimento de empreendimentos desse porte. A discussão mais recente sobre o tema, em especial com relação aos 
Quadro I - Tipologias de Grandes Projetos Urbanos no cenário brasileiro

\begin{tabular}{|c|c|c|c|}
\hline Tipos & Características & Oportunidades para implantação & Escalas de intervenção \\
\hline Obras & Obras de infraestrutura pesada & $\begin{array}{l}\text { Crescimento urbano e demandas } \\
\text { por infraestrutura básica }\end{array}$ & $\begin{array}{l}\text { Possibilidade de alcance da } \\
\text { cidade como um todo }\end{array}$ \\
\hline Marcos arquitetônicos & $\begin{array}{l}\text { Projetos de arquitetura com } \\
\text { produção de intervenções pontuais, } \\
\text { geralmente com assinatura de } \\
\text { arquiteto renomado }\end{array}$ & $\begin{array}{l}\text { Criação de referências } \\
\text { arquitetônicas }\end{array}$ & $\begin{array}{l}\text { Espaços restritos, relacionados } \\
\text { ao entorno imediato da } \\
\text { intervenção }\end{array}$ \\
\hline Espaços arquitetônicos & $\begin{array}{l}\text { Tratamento dos espaços urbanos } \\
\text { para a criação de locais com caráter } \\
\text { atrativo }\end{array}$ & Promoção de espaços urbanos & $\begin{array}{l}\text { Espaços restritos, relacionados } \\
\text { ao entorno imediato da } \\
\text { intervenção }\end{array}$ \\
\hline Megaeventos & $\begin{array}{l}\text { Eventos demandantes de amplas } \\
\text { instalações para sua realização }\end{array}$ & $\begin{array}{l}\text { Adequação das cidades para } \\
\text { recepção de eventos de grande } \\
\text { porte }\end{array}$ & $\begin{array}{l}\text { Possibilidade de alcance da } \\
\text { cidade como um todo }\end{array}$ \\
\hline
\end{tabular}

Fonte: Adaptado de Gadens e colaboradores (2011).

eventos da Copa do Mundo de 2014 e dos Jogos Olímpicos de 2016, tem evidenciado violações de direitos e exclusão de comunidades na definição sobre remoções necessárias à implantação dos projetos, em um contexto político de recentralização administrativa e decisões autoritárias (Vainer, 2011). Essas violações de direitos para viabilização dos jogos focam-se, sobretudo, na questão do direito de moradia, tendo como destaque as desapropriações de populações carentes que residem próximas aos locais dos eventos, gerando tensões entre os interesses públicos e privados e as demandas e necessidades dessas comunidades. Tais ocorrências foram recorrentes durante o processo preparatório dos Jogos Pan-americanos de 2007, quando também foram removidas famílias carentes situadas próximas aos locais de competição, a partir de decisão unilateral do poder público e dos investidores privados.

Nesse sentido, Rolnik (2011) afirma que a prática de "exceções" torna-se recorrente quando se trata da realização de megaeventos esportivos. "É quando nenhum dos direitos e nenhuma das legalidades que foram duramente conquistados precisam ser respeitados, isso em função da celeridade das obras, comprometidas com o fato de as cidades serem sedes dos Jogos da Copa do Mundo, e, no caso do Rio, também da Olimpíada” (Rolnik, 2011, [s.p.]). Esse fato implica em desafios impostos na implantação de GPUs sob a ótica das decisões políticas e de gestão das cidades que os recebem, na tentativa de estender os benefícios oriundos desses projetos a toda a população.

Reconhecidas as devidas limitações na proposição da tipificação apresentada no Quadro 1, tornase relevante a apropriação do tema sob a égide da construção e discussão dos conceitos propostos. Assim, adiante é discutida a implantação desses tipos de GPUs relacionados aos modelos e práticas de gestão urbana brasileira, ao longo de quatro décadas consideradas.

\section{Da Concepção dos Grandes Projetos Urbanos nos Modelos de Gestão}

Considerando as características das cidades brasileiras com suas demandas sociais expressivas, a frequência de implantação de GPUs ainda é reduzida, uma vez que tais projetos concorrem diretamente com outras medidas e ações que compõem uma política urbana nacional, a qual ainda prioriza projetos e programas de atendimento às demandas urbanas básicas, como saneamento, habitação e transporte, além da criação dos planos diretores municipais e a aplicação mais sistemática dos instrumentos do Estatuto da Cidade (Ultramari e Rezende, 2007).

Na década de 1970, destacou-se no Brasil a implantação de grandes infraestruturas que objetivavam suprimir as necessidades decorrentes da industrialização acelerada, a qual teve início a partir de meados da década de 1950 (Bortoleto, 2001). Nessa 
época, devido ao acentuado crescimento urbano, o Estado se deparou com a necessidade de empreender projetos de caráter emergencial e de estruturas pesadas, como hidrelétricas, entre outros exemplos. Portanto, embora essas obras nem sempre tenham sido realizadas em áreas urbanas, sua execução se destinava ao atendimento das necessidades existentes nas cidades.

Bortoleto (2001) denomina essas intervenções megaprojetos e considera que correspondem a estratégias de desenvolvimento que pretendiam promover a redução das desigualdades inter-regionais. Esse tipo de intervenção, que ganha força no Brasil durante o período militar, tinha por meta a tomada ostensiva de territórios até então não ocupados e sujeitos ao domínio de forças estrangeiras (Ultramari e Rezende, 2007).

No entanto, segundo Vainer e Araujo (1992, p. 33), "às regiões de implantação, de modo geral, tem restado a desestruturação das atividades preexistentes, o crescimento desordenado da população, desemprego, favelização, marginalização social, e, quase sempre, degradação ambiental”. Nesse sentido, essas grandes obras são apresentadas como potencializadoras do desenvolvimento nacional, mas, na prática, seus efeitos não foram revertidos em benefícios à população local diretamente impactada, mas, como ressaltam os dois autores, acabaram beneficiando apenas o centro hegemônico da economia. Discussões dessa mesma natureza podem ser evidenciadas nas políticas de promoção de GPUs anos mais tarde, nas décadas de 1980, 1990 e 2000.

A despeito desse fato, o contexto que envolveu a implantação de grandes projetos nesse período buscava "estimular novos processos urbanos que transformariam as cidades e trariam desenvolvimento a todo o país" e "atender a uma política de ordenação do território nacional que buscava diminuir as disparidades existentes" (Ultramari e Rezende, 2007, p. 4).

Embora com origens e justificativas distintas dos GPUs que viriam a ser implantados nas décadas subsequentes, podem ser identificadas similaridades conceituais na concepção das intervenções produzidas nos anos 1970, reforçando a conceituação de Grandes Projetos Urbanos. Essas similaridades residem, sobretudo, no envolvimento de elevadas somas de recursos financeiros para a sua viabilização. Além disso, impactos no âmbito social, e até mesmo ambiental, resultantes da implantação desses projetos, foram relegados a um segundo plano, igualmente quando se discute, anos mais tarde, a questão de GPUs como causadores ou potencializadores de processos de gentrificação mesmo em um cenário voltado à melhor articulação com a sociedade, promovendo em alguns casos acentuação de conflitos sociais já existentes.

Considerando a discussão do tema sob a ótica da gestão, observa-se que, se na década de 1970 as decisões político-administrativas eram centradas na figura do Estado, e a partir dos anos 1980 os municípios se dedicaram ao fortalecimento do seu papel como gestores de políticas públicas (Rolnik e Someck, 200o). Nesse cenário, também se evidenciaram novas formas de articulação com a sociedade no que se refere a recursos e financiamentos para a viabilização de projetos de amplas proporções, como os dos GPUs.

Com as mudanças dos regimes políticos no processo de redemocratização na América Latina e as reformas de Estado, a partir dos anos 1980 e com maior ênfase nos anos 1990, num contexto de enfraquecimento do Estado e em função de uma progressiva globalização política e econômica, a cidade voltou a ser gerida seguindo padrões democráticos. Faz parte desse contexto o processo de reformulação política, com o fortalecimento do presidencialismo, mudanças institucionais variadas e uma promoção geral da descentralização do Estado, apresentando consequências na lógica de urbanização e para a governança urbana na América Latina (Carrión, 2007).

O Estado, que na década de 1970 era ainda forte e centralizador de decisões com visão tecnicista, passou a ter a necessidade de se reestruturar na medida em que as cidades ganhavam dimensões globalizadas. Segundo Carrión (2007), uma das grandes tendências de mudança na gestão pública consistiu na sua privatização em todos os seus sentidos.

A entrada do setor empresarial privado (nacional e internacional) produz uma transformação dos marcos institucionais e das modalidades de gestão. A privatização faz com que a cidade comece a ser vítima do abandono do cívico, da perda de sua 
condição de espaço público e do fortalecimento da exclusão dos setores populares (p. 48).

Dessa forma, nos anos 1980, o Brasil enfrentou o enfraquecimento do planejamento regulatório estatal, fato que não impediu a existência de algumas iniciativas de caráter local do que se poderia chamar de Grandes Projetos Urbanos. Essas intervenções correspondiam a ações voltadas para a recuperação de áreas centrais, para a valorização de regiões costeiras e ribeirinhas e para o resgate do patrimônio histórico, entre outras. Para Ultramari e Rezende (2007), esses esforços podem ser considerados como GPUs em função dos impactos gerados em seus espaços urbanos imediatos e não necessariamente em razão do tamanho e complexidade de suas obras. Autores como Oliveira e Lima Junior (2009) afirmam que, nacionalmente, o planejamento urbano e regional vem sofrendo mudanças significativas a partir da década de 199o. Nesse período, ganhou destaque a difusão de modelos de intervenção sobre o território oriundos, sobretudo, das experiências europeias.

Nesse contexto, com a importância destinada aos GPUs a partir da década de 1990, novas práticas e instrumentos de planejamento ganharam relevância, angariando o apoio de instituições na forma de recursos financeiros ou de estudos que funcionaram como chancela para novas práticas (Oliveira e Lima Junior, 2009). Dessa forma, com novos marcos regulatórios que não existiam na década de 1970, passaram também a ser considerados impactos sociais e ambientais provenientes da implantação de alguns GPUs. Ou seja, se anteriormente esses impactos eram aceitáveis até certo ponto, agora tornava-se necessária a realização de análises prévias que considerassem medidas compensatórias para minimizar ou anular os efeitos deletérios. No Brasil, esse fato se reproduziu com a exigência da elaboração de estudos de impacto ambiental, que refrearam, em certa medida, a presença de GPUs no território nacional.

Ainda considerando a década de 1990 como recorte histórico, observa-se que nas cidades brasileiras foi recorrente a implementação de empreendimentos de valorização e revitalização de áreas centrais degradadas e de setores históricos subutilizados, entre outros espaços urbanos (Ultramari e Rezende, 2007).
Estes grandes projetos de valorização das áreas centrais, frequentemente apresentando um grande potencial de dinamização econômica, foram se aliando aos objetivos e anseios dos projetos de Reforma do Estado, que apostou na crescente articulação e cooperação entre poder público e setor privado para a implementação de GPUs, iniciando, a partir da década de 1990, uma nova fase, caracterizada por um "empreendedorismo urbano" (Compans, 2005), com as grandes cidades assumindo um papel bem mais proativo no campo econômico, além de recorrer à prática do Planejamento Estratégico na definição de suas prioridades de desenvolvimento. Nesse contexto, os GPUs foram idealizados comumente como projetos de revitalização urbana. Nesse sentido, Hall (1998, p. 412) comenta que:

A receita mágica para a revitalização urbana - a palavra-isca norte-americana que passou a circular em todos os projetos para esse fim - parecia consistir num novo tipo de parceria criativa, expressão incessantemente utilizada pelos norte-americanos, entre o governo municipal e o setor privado.

Faz parte também desse processo o conceito de city marketing, como orientação da política urbana para criação ou atendimento das necessidades dos consumidores, sejam esses empresários, turistas ou os próprios cidadãos (Sanchez, 1999).

Nesse âmbito, observa-se que as cidades foram pensadas e produzidas com vistas à sua inserção no circuito mundial de valorização, prevendo adequação nas formas de planejamento e gestão urbana, inclusive com a adoção de princípios de planejamento estratégico; isto foi interpretado por Guell (2006) como um processo sistemático, criativo e participativo, que define um modelo futuro de desenvolvimento da cidade. Sanchez e colaboradores (2004, p.41), no entanto, chamam a atenção para a dimensão político-ideológica envolvida:

Competividade, "empresariamento", planejamento estratégico por projetos, intervenções pontuais, entre outros anunciados, passam a compor o rol das iniciativas a serem adotadas pelos administradores urbanos dos mais diversos matizes políticoideológicos.

Segundo Vainer (2000), o planejamento estratégico encontra-se entre os modelos que concorreram 
para ocupar o espaço deixado pela derrocada do tradicional padrão tecnocrático-centralizado-autoritário, que se observava na década de 1970. Esse modelo vem sendo difundido no Brasil e na América Latina, envolvendo agências multilaterais (Banco Internacional para Reconstrução e Desenvolvimento - BIRD, Habitat etc.) e consultores internacionais voltados para o discurso do sucesso de GPUs. Segundo Borja (1995, p. 276), esse tipo de planejamento está associado ao fato de que "as cidades se conscientizam da mundialização da economia e da comunicação [...]" e, consequentemente, "se produz crescente competição entre territórios e especialmente entre seus pontos nodais ou centros, isto é, as cidades".

Nesse contexto, nos últimos anos, é possível observar que, no "mercado de cidades", tornou-se necessário garantir um diferencial que destaque determinado centro urbano em relação aos demais. Sobre o assunto, Arantes (200o) comenta que as cidades só se tornarão privilegiadas se, e somente se, forem dotadas de um plano estratégico que detenha respostas competitivas aos desafios da globalização.

Assim, os GPUs, na fase do empreendedorismo urbano, se transformaram em um tipo de manifestação do fenômeno de competição global entre cidades. Ferrán (2001, p. 243) teme que desta forma "as grandes cidades estão aumentando sua dependência de capitais, bem como de fatores exógenos sobre os quais elas têm pouco controle, mas que precisam atrair para poder competir e manter seu ritmo de desenvolvimento".

A controvérsia local é um fator comum entre os habitantes das cidades que recebem empreendimentos dessa natureza. Se, de um lado, há o entendimento de que são necessários para a sua inserção em um nível globalizado de competição, por outro, surgem dúvidas diante da percepção de que os benefícios oriundos desses Grandes Projetos Urbanos acabam ficando somente para os investidores e as instituições alheias à cidade, em detrimento da população, de modo geral, que muitas vezes fica até com prejuízos oriundos dos efeitos socioambientais negativos de tais projetos.

Conforme Machado (2004), as políticas públicas atuais estruturam-se com base em eficientes estratégias de marketing, com a finalidade de produzir uma imagem forte e competitiva da cidade, ao passo que também procuram a construção de um perigoso consenso, com a aceitação passiva da população em relação aos mecanismos dessas estratégias. Essa condução pode encobrir riscos sociais existentes, dificultando a efetiva participação da sociedade.

Assim, a crítica recorrente à política de implantação dessas intervenções afirma que "enquanto um setor da sociedade enriquece e melhora sua qualidade de vida, outro setor se vê cada vez mais marginalizado e suas carências aumentam dia a dia” (Roitman, 2001). Segundo Limonad (2005), o que ocorre é a valorização desigual de partes da cidade, uma vez que a cidade não é mais pensada para o uso de seus habitantes, mas meramente para o consumo global.

A despeito das críticas com relação às consequências observadas em decorrência das políticas públicas de implantação de GPUs, esse trabalho procura investigar a relação institucional e de gestão dessa prática no Brasil. Nesse sentido, uma mudança decisiva nesse contexto, em razão do que era praticado na década de 1970, consistiu no fato de grande parte das empresas e de seus empreendimentos territoriais não estar mais sob o controle do Estado brasileiro (Vainer, 2007). Considerando o cenário de efetivação de parcerias público-privadas, verificou-se o crescente envolvimento do setor privado em substituição às práticas urbanísticas de domínio exclusivo dos governos.

Já na década de 200o, também se observou, como nos moldes de planejamento proposto pelo Estado, a tentativa de implementação de GPUs por meio de um processo de gestão mais democrático e preocupado com os impactos dessas intervenções sobre os aspectos físicos, ambientais e sociais, embora persista a crítica recorrente sobre a forma como essa participação é promovida na implantação dessas intervenções.

No entanto, pode-se afirmar que uma das potencialidades da utilização da participação popular no processo de gestão urbana consiste na mobilização dos conhecimentos da sociedade em prol da construção de políticas públicas e ações de planejamento urbano. Segundo Frey (2007), o tema governança tem sido enfatizado inclusive na academia, salientando a necessidade de detenção desse conhecimento 
existente na sociedade em benefício da melhoria do desempenho administrativo e da democratização dos processos decisórios locais.

Assim, recentemente, observa-se a busca de maior representação política por meio de uma aproximação entre Estado e sociedade, com o fortalecimento do poder local e o desenvolvimento de processos de descentralização pela abertura de novos canais de participação. No entanto, embora a política de governança democrática seja recorrente no atual modelo brasileiro, tal fato parece não se materializar na viabilização de GPUs. Segundo Vainer (2007), os processos decisórios que dão origem a esses projetos quase sempre acontecem nos corredores e gabinetes, em espaços informais e à margem do exercício do planejamento territorial ou de qualquer debate público.

Someck e Campos Neto (2005, [s.p.]) comentam que "o risco de potencializar os efeitos excludentes da urbanização contemporânea, que caracteriza os grandes projetos urbanos estratégicos das últimas décadas, coloca em questão a capacidade e as limitações do poder local no quadro de globalização”.

Dessa forma, discute-se que as soluções para os problemas urbanos passam pelo envolvimento dos atores locais, da sociedade civil e das diferentes esferas de governo, inclusive, embora ainda pouco aplicadas, na concepção de GPUs. Apesar dessa necessidade, ainda são raras as oportunidades proporcionadas à sociedade para sua contribuição no processo de elaboração de intervenções desse porte.

As decisões autoritárias provindas do Estado, constatadas no país na década de 1970, não encontram mais espaço de aplicação, uma vez que se coloca a necessidade de envolvimento de agentes sociais na busca de processos compartilhados de gestão urbana, em que se pretende, inclusive, evitar as consequências excludentes de ações de renovação urbana, por exemplo, viabilizadas por meio de um GPU. No entanto, ainda há um longo caminho a percorrer para que o envolvimento desses agentes sociais seja efetivado nas discussões acerca da implementação de Grandes Projetos Urbanos.

\section{Considerações Finais}

Embora a construção do conceito de Grandes Projetos Urbanos ainda seja um processo em discussão na academia, é possível diagnosticar visões contrárias e favoráveis à sua implementação, que ora consideram sua implantação como uma apropriação indevida de espaços por uma minoria da população, ora reconhecem seu papel na recuperação de áreas degradadas e assimilação de infraestruturas subutilizadas.

Observa-se que, a partir do delineamento temporal proposto para análise, o qual considera as principais características dos modelos de gestão reconhecidos nas últimas quatro décadas, ocorreram alterações na forma de concepção e implementação dos GPUs no país. No entanto, sua essência esteve invariavelmente alinhada com a proposição dos modelos de gestão que estavam sendo aplicados, ora com base no poder centralizador do Estado, que financiava grandes obras de infraestrutura, ora com a abertura para a participação mais democrática da sociedade, ainda que venha sendo questionada a sua aplicabilidade na implementação de GPUs;no entanto, ainda faltam experiências para uma possível avaliação mais criteriosa.

0 que se evidencia como aspecto comum à implementação dos GPUs, nas diferentes décadas de análise, é a dificuldade - ou falta de disposição - de inserir a população em processos decisórios em torno de projetos de grande porte, quando grandes volumes de recursos estão em jogo e os potenciais impactos sociais e ambientais tendem a ser substantivos. Embora essa não fosse uma prática pertinente ao modelo de gestão da década de 1970, mesmo nos anos posteriores, com a abertura democrática de participação, são observados entraves à consideração e inclusão das comunidades na discussão de Grandes Projetos Urbanos.

Enquanto o Estado, na época do autoritarismo burocrático, ainda dispunha de meios impositivos para assegurar, embora precariamente, essa posição, hoje, em tempos de consolidação democrática e de crescente vigilância por parte da sociedade civil, o alcance da legitimidade política passa necessariamente pelo aprimoramento das práticas dialógicas e deliberativas na relação entre Estado e sociedade (Frey, 2007).

Embora a participação comunitária seja inerente ao modelo de planejamento estratégico utilizado nas décadas de 1990 e 2000 , a sua adoção pelas 
administrações públicas ainda tende a privilegiar o atendimento às necessidades dos investidores, não considerando a representatividade de todos os setores sociais no processo de planejamento de cidades ou de grandes projetos. Assim, GPUs vinculados a grandes obras de infraestrutura, comuns na década de 1970 no cenário nacional, tendem a abordagens tecnocráticas ou gerenciais, enquanto aqueles referentes a marcos e espaços arquitetônicos, voltados à promoção de áreas mais restritas relacionadas ao entorno imediato da intervenção, deveriam permitir uma participação mais ampla da população, embora essa não seja uma prática corrente no país. Por sua vez, os megaeventos, com prazos predefinidos, tendencialmente privilegiam atitudes governamentais mais centralizadoras.

Numa sociedade em que práticas autoritárias de gestão pública encontram cada vez menos respaldo da sociedade, novas formas democráticas de governança precisam ainda ser desenvolvidas, visando conciliar a participação da sociedade com as exigências técnicas colocadas pela complexidade de tais projetos. A capacidade de intermediação entre política e sociedade torna-se um dos grandes desafios dos gestores urbanos na busca da legitimidade democrática. A inserção da prática participativa busca também a minimização dos riscos que envolvem um GPU, bem como suas externalidades e impactos negativos.

Se, por um lado, testemunha-se avanços significativos nas últimas décadas, envolvendo o aprofundamento da democracia local em diversos campos de políticas públicas e de gestão, tal prática ainda não se estende às experiências de implementação de Grandes Projetos Urbanos. De outra forma, as próprias pesquisas e a reflexão acadêmica se revelam relativamente omissas em relação à busca de melhor entendimento das condicionantes de práticas democráticas de elaboração e implementação de GPUs. É provável que vindouros mega eventos esportivos, como a Copa do Mundo e as Olimpíadas, promovam oportunidades interessantes para avançarmos nesse campo, tanto com relação às práticas democráticas de gestão de GPUs quanto com referência às condicionantes e fatores para seu êxito.

\section{Referências}

ALTSHULER, A.; LUBEROFF, D. The changing politics of Urban Mega Projects. Land Lines, Boston, v. 15, n. 4, p. 45-75, Oct. 2003.

ARANTES, O. Uma estratégia fatal: a cultura nas novas gestões urbanas. In: ARANTES, O.; VAINER, C.; MARICATO, E. (Org.) A cidade do pensamento único. Petrópolis: Vozes, 200o. p. 11-74.

BECK, U. Risk society - towards a new modernity. London: Sage, 1992.

BORJA, J. Barcelona: un modelo de transformación urbana. Quito: Programa de Gestión Urbana / Oficina Regional para América Latina y Caribe, 1995.

BORJA, J.; CASTELLS, M. Local y global: la gestión de las ciudades en la era información. México, D. E.: Santillana; United Nations for Human Settlements; Taurus, 200o. (inicialmente publicado em Madrid, 1997).

BORTOLETO, E. M. A implantação de grandes hidrelétricas: desenvolvimento, discurso e impactos. Revista Geografares, Vitória, n. 2, p. 5362, 2001.

CARRIÓN, F. El desafio político de gobernar la ciudad. Nueva Sociedad, Buenos Aires, n. 212, p. 36-52, 2007.

COMPANS, R. Empreendedorismo urbano: entre o discurso e a prática. São Paulo: Editora da Unesp, 2005.

DEL RIO, V. Em busca do tempo perdido. 0 Renascimento dos centros urbanos. Arquitextos oo6, São Paulo, Texto Especial 028, nov. 2000. Disponível em: <http://www.vitruvius.com.br/ arquitextos/arqooo/espo28.asp>. Acesso em: 15 nov. 2010.

FERRÁN, C. O efeito territorial dos "Grandes Projetos Urbanos”. In: ABRAMO, P. (Org.) Cidades em transformação: entre o plano e o mercado; experiências internacionais de gestão do solo urbano. Rio de Janeiro: Observatório Imobiliário e de Políticas do Solo, 2001. p. 239-26o. 
FREY, K. Governança urbana e participação pública. RAC - eletrônica - Revista de Administração Pública, Rio de Janeiro, n.1, p.136150, 2007. Disponível em: <http://www.anpad.org. br/periodicos/arq_pdf/a_629.pdf $>$. Acesso em: 22 dez. 2010.

GADENS, L. N.; HARDT, L. P. A.; FREY, K. Grandes projetos urbanos: evolução conceitual à luz da gestão urbana brasileira. In: ENCONTRO NACIONAL DA ASSOCIAÇÃO NACIONAL DE PÓSGRADUAÇÃO E PESQUISA EM PLANEJAMENTO URBANO E REGIONAL, 14., Rio de Janeiro, 2011. Anais eletrônicos... Rio de Janeiro: Enanpur, 2011. 1 CD-ROM.

GUELL, J. M. F. Planificación estratégica de ciudades: nuevos instrumentos y procesos. Barcelona: Reverté, 2006.

HALL, P. Cidades do amanhã. São Paulo: Perspectiva, 1998.

HARDT, L. P. A. et al. Grandes projetos urbanos: impactos do Plano Serete sobre a morfologia e a paisagem do ambiente construído de Curitiba, Paraná. In: ENCONTRO DA ASSOCIAÇÃO NACIONAL E PESQUISA E PÓS-GRADUAÇÃO EM AMBIENTE E SOCIEDADE, 4., Brasília, 2008. Anais... Brasília: ANPPAS, 2008. p.1-18. 1 CD-ROM.

HARVEY, D. Spaces of hope. Berkeley: University of California Press, 2000.

LIMONAD, E. Estranhos no paraíso (de Barcelona): impressões de uma geógrafa e arquiteta brasileira residente em Barcelona. Revista Bibliográfica de Geografia y Ciencias Sociales, Barcelona, v.X, 2005. Disponível em: <http://www.ub.edu/geocrit/ b3w-610.htm>. Acesso em: 13 maio 2011.

MACHADO, T. R. Para a "Cidade Maravilhosa", um "Plano Maravilha": uma leitura crítica sobre produção da imagem turística e marketing urbano no Rio de Janeiro. 2004. 174 f. Dissertação (Mestrado em Planejamento Urbano e Regional) - Instituto de Pesquisa e Planejamento Urbano e Regional, Universidade Federal do Rio de Janeiro, Rio de Janeiro, 2004.
MOULAERT, F.; RODRIGUEZ, A.; SWYNGEDOUW, E. The globalized city: economic restructuring and social polarization in european cities. Oxford: Oxford University Press, Oxford Geographical and Environmental Studiesed, 2003.

OLIVEIRA, F. L.; LIMA JUNIOR, P. N. Grandes projetos urbanos: panorama da experiência brasileira. In: INTERNATIONAL CONGRESS OF THE LATIN AMERICAN STUDIES ASSOCIATION, 28., Rio de Janeiro, 2009. Anais eletrônicos... Disponível em: <http://lasa.international.pitt. edu/members/ congresspapers/lasazoog/files/ OliveiraFabricioLeal.pdf >. Acesso em: 20 out. 2010. POWELL, K. City transformed: urban architecture at the beginning of the 21st century. New York: Neues, 2000.

ROITMAN, S. Transformaciones urbanas em los 90: los barrios cerrados del área metropolitana de Mendoza. Revista Mundo Urbano, Buenos Aires, n. 13, set./out., 2001. Disponível em: <http://www. mundourbano.unq.edu.ar/index.php?option=com content\&task $=$ view\&id=104\&Itemid=43>. Acesso em: 15 maio 2011.

ROLNIK, R., SOMECK, N. Governar as metrópoles: dilemas da recentralização. São Paulo em Perspectiva, São Paulo, n. 4, p. 83-9o, 2000.

ROLNIK, R. Copa, olimpíadas e violações de direitos no Brasil. abr. 2011. Disponível em: <http://raquelrolnik.wordpress.com/2011/04/05/ copa-olimpiadas-e-violacoes-de-direitos-nobrasil/>. Acesso em: 14 maio 2011.

SANCHEZ, F. Políticas urbanas em renovação: uma leitura dos modelos emergentes. Revista Brasileira de Estudos Urbanos e Regionais, Campinas, n. 1, p. 115-132, 1999.

SANCHEZ, F. et al. Notas para recuperar a emergência histórica dos grandes projetos urbanos. Revista Paranaense de Desenvolvimento, Curitiba, n. 107, p. 39-56, jul./dez. 2004.

SANTOS, J. C. Reflexões por um conceito contemporâneo de urbanismo. Revista Lusófona de Urbanismo, Lisboa, n.3, 20o6. Disponível em: <http://revistas.ulusofona.pt/index.php/ malhaurbana/article/view/87>. Acesso em: 13 maio 2011. 
SOMECK, N.; CAMPOS NETO, C. M.

Desenvolvimento local e projetos urbanos.

Arquitextos 059, Texto Especial 059, abr. 2005. Disponível em: <http://www.vitruvius.com.br/ revistas/read/arquitextos/o5.059/470>. Acesso em: 28 out. 2010 .

ULTRAMARI, C.; REZENDE, D. A. Grandes projetos urbanos: conceitos e referenciais. Ambiente Construído, Porto Alegre, v. 7, p. 1-15, 2007. Disponível em: <http://www.seer.ufrgs. br/index.php/ambienteconstruido/article/ viewArticle/3733>. Acesso em: 21 out. 2010.

VAINER, C. Pátria, empresa e mercadoria: notas sobre a estratégia discursiva do Planejamento Estratégico Urbano. In: ARANTES, O.; VAINER, C.; MARICATO, E. (Org.) A cidade do pensamento único. Petrópolis: Vozes, 200o. p. 75-104.
VAINER, C. Planejamento territorial e projeto nacional: os desafios da fragmentação. Estudos Urbanos e Regionais, Niterói, v. 9, p. 9-23, 2007. Disponível em: <http://www.anpur.org.br/revistas/ rev_ANPUR_v9_n1.pdf $>$. Acesso em: 02 dez. 2010.

VAINER, C. Cidade de exceção: reflexões a partir do Rio de Janeiro. In: ENCONTRO NACIONAL DA ASSOCIAÇÃO NACIONAL DE PÓS-GRADUAÇÃO E PESQUISA EM PLANEJAMENTO URBANO E REGIONAL 14., Rio de Janeiro, 2011. Anais eletrônicos... Rio de Janeiro: Enanpur, 2011. 1 CDROM.

VAINER, C. B.; ARAUJO, F. G. B. de. Grandes projetos hidrelétricos e desenvolvimento regional. Rio de Janeiro: Centro Ecumênico de Documentação e Informação - CEDI, 1992. 